\title{
Thermal Modeling of Automotive Lithium Ion Cells using the Finite Elements Method in Modelica
}

\author{
Imke Krüger Martin Sievers Gerhard Schmitz \\ Institute of Thermofluid Dynamics, Applied Thermodynamics \\ Hamburg University of Technology, 21071 Hamburg, Germany \\ \{imke.krueger, martin.sievers, schmitz\}@ tuhh.de
}

\begin{abstract}
In this paper, a finite element model for the heat transfer inside an automotive lithium ion cell with Modelica is developed. Convective cooling with several coolants is examined. With the help of the cell model, the effectiveness of several coolants are investigated. As coolants air, 25 and $38 \%(\mathrm{v} / \mathrm{v})$ aqueous propylene glycol, and a silicone oil are used.

Keywords: lithium ion cell; Modelica; OpenModelica Compiler; heat transfer; finite element method
\end{abstract}

\section{Introduction}

Lithium ion cells are a promising technology for the use in hybrid vehicles due to their high energy and power densities. However, thermal management is necessary to prevent premature aging, and for safety reasons. The modeling and simulation of the temperature distribution in a lithium ion cell is therefore of high interest for the design of a cooling system. Heat sink for the cells is the automotive refrigeration cycle. since the refrigeration cycle will be modeled in Modelica it is obvious to model the battery pack with Modelica as well. In this way, one can avoid time-consuming coupling with other software packages.

Due to the anisotropic heat conduction and the distributed heat generation inside the cell, a simple lumped capacity model is not sufficient to assure that the maximum temperature inside the cell is kept beyond a certain level. To determine the temperature distribution in a cylindrical $\mathrm{Li}$-ion cell, a two-dimensional finite element model is developed and presented in this paper [1]. The thermal models are simulated with Dymola and the OpenModelica Compiler in combination with the GUI simforge.

The paper is structured as follows. The following section describes the structures of the Lithium ion cell and the cooling system. In Section 3, the idea of the finite element method is presented and its Modelica implementation illustrated. In Section 4, the results for several coolants are compared. Conclusions are drawn in the final section.

\section{Lithium Ion Cells}

Li-ion cells are characterized by the type of electrolyte that is used, the geometry of the cell, the type of the electrodes and the material of the electrodes and other parts. In this project the temperature of a commonly used cell type is simulated.

Fig. 1 shows the architecture of a spirally wound cylindrical cell.

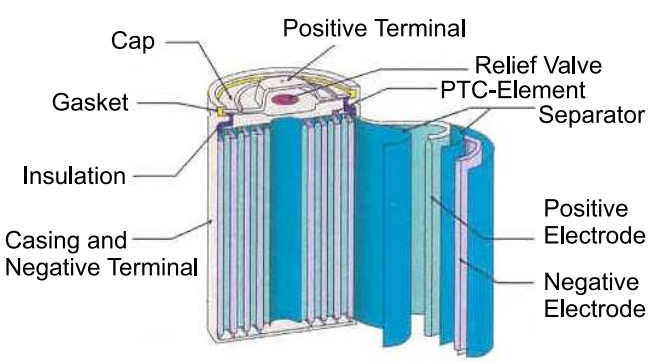

Figure 1: Architecture of a spirally wound cell [2]

A winding consisting of a negative electrode with a negative conductor, a separator layer, a positive electrode with a positive conductor and a further separator layer is rolled up and put in a metal casing. This casing is then filled up with the electrolyte. The investigated cell has a $\mathrm{LiCoO}_{2}$ positive electrode with an aluminum conductor, a graphite negative electrode with a copper conductor and PE/PP separators. The casing is made of steel. The cylindrical cell uses the standard electrolyte $\mathrm{LiPF}_{6}$. Many commercially available cells are 


\begin{tabular}{lc}
\hline Material & Thermal Conductivity $/ \frac{\mathrm{W}}{\mathrm{mK}}$ \\
\hline Steel & 15 \\
$\mathrm{LiPF}_{6}$ & 0.6 \\
Aluminum & 240 \\
$\mathrm{PE} / \mathrm{PP}$ & 0.22 \\
Graphite & 1.04 \\
Copper & 395 \\
$\mathrm{LiCoO}_{2}$ & 1.58 \\
\hline
\end{tabular}

Table 1: Thermal conductivity of the cell components $[3,4,5,6,7]$

based on this $\mathrm{LiCoO}_{2}$-graphite system. Thermal conductivities of the cell materials are listed in Table 1. In this model 31 windings are used, the foil thicknesses from 20 to $140 \mu \mathrm{m}$ are used. This results in a capacity around 7.5 Ah.

To construct an HEV battery pack, many Li-ion cells are connected serial and parallel within the pack. An essential part of the battery pack is its thermal and electrical management. Current and voltage of every single Li-ion cell in a battery pack must be controlled because overcharging can lead to thermal runaway. As heat is generated continuously within the cell during charging and unloading, an appropriate cooling system is necessary.

Cell performance generally improves with increasing temperature, as diffusive processes dominate the reaction. On the other hand ageing processes become faster as well with increasing temperatures. At room temperature the reduction of cell life can reach up to $50 \%$ for a temperature increase of $10 \mathrm{deg}$ C. A thermal management system ensures a long life time and good cell performance. At temperatures above $70^{\circ} \mathrm{C}$ the cell is at risk of thermal runaway. The separator melts and direct contact between the electrodes results in a highly exothermic reaction. The optimum balance between long life time and cell performance is achieved when the mean temperature lies between 25 and $30^{\circ} \mathrm{C}$ [2]. The maximum temperature within the cell should exceed $40^{\circ} \mathrm{C}$ in exceptional cases only [2]. Temperature differences within the cell lead to mechanical stress. One measure of this stress is the maximum temperature difference, which should not exceed $5 \operatorname{deg} \mathrm{C}$.

These limits have to be fullfilled for a variety of boundary conditions because the same battery system has to operate efficiently in different climates. Three different cooling systems are possible in a hybrid vehicle:
- air cooling: the air is provided by the air conditioning system,

- secondary loop cooling: a coolant is circulated in an additional loop,

- evaporative cooling: the battery heat exchanger is connected to the refrigeration unit of the air conditioning.

In this paper, the first two approaches are investigated. Forced convection in the longitudinal direction is directly applied to the cell shell and natural convection to the caps. The configuration is shown in Fig. 2.

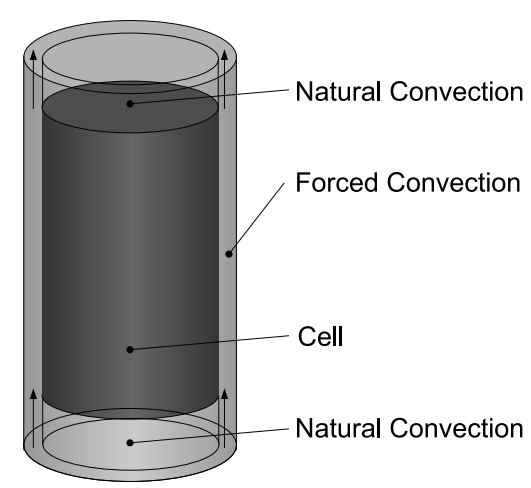

Figure 2: Configuration of the heat transfer at the cell surface

\section{Finite Element Method}

\subsection{Mathematical Aspects}

The finite element method is widely used for mechanical problems, but can also be successfully applied to heat transfer problems. This applies especially to problems, for whom an analytical solution is difficult to find due to complex geometries or heat generation inside the object of interest.

The temperature distribution inside the cell is independent of the circumferencial direction if longitudinal flow of the coolant is assumed. The Fourier differential equation of heat transfer in cylindrical coordinates:

$\lambda\left[\frac{1}{r} \frac{\partial}{\partial r}\left(r \frac{\partial \vartheta}{\partial r}\right)+\frac{1}{r^{2}} \frac{\partial^{2} \vartheta}{\partial \varphi^{2}}+\frac{\partial^{2} \vartheta}{\partial z^{2}}\right]+\dot{e}=\rho c_{p} \frac{\partial \vartheta}{\partial t}$

is reduced to two dimensions. With the assumption of constant radial und axial heat conductivity, it can be 
further simplified to

$$
\frac{1}{r}\left[\lambda_{r} \frac{\partial}{\partial r}\left(r \frac{\partial \vartheta}{\partial r}\right)\right]+\lambda_{z} \frac{\partial^{2} \vartheta}{\partial z^{2}}+\dot{e}=0
$$

with the following boundary conditions

$$
\vartheta=\vartheta_{b}
$$

and

$$
\lambda_{r} \frac{\partial \vartheta}{\partial r} l+\lambda_{n} \frac{\partial \vartheta}{\partial z} n+\alpha\left(\vartheta-\vartheta_{i n f}\right)+\dot{q}=0 .
$$

Equation (3) defines temperatures at the boundaries (Dirichlet boundary conditions). A heat flux can be prescribed by (4), it considers a heat flux due to heat conduction or convection as well as a given heat flux $\dot{q}$ (Neumann boundary condition).

To model a certain cylinder, the area is subdivided into elements. In this approach, triangular elements with linear basis functions are used[8].

For each element, a stiffness matrix $\mathbf{S}$ and the load vector $\vec{b}$ are calculated. The stiffness matrix $\mathbf{S}$ defines the heat conduction inside the triangle:

$$
\mathbf{S}=\int_{V} \mathbf{B}^{\mathbf{T}} \mathbf{D} \mathbf{B} d V+\int_{O} \alpha \mathbf{N}^{\mathbf{T}} \mathbf{N} d O
$$

with

$\mathrm{B}=\left[\begin{array}{c}\frac{\partial \vartheta}{\partial r} \\ \frac{\partial \vartheta}{\partial z}\end{array}\right]=\left[\begin{array}{c}\frac{\partial N_{1}}{\partial r} \frac{\partial N_{2}}{\partial r} \frac{\partial N_{3}}{\partial r} \\ \frac{\partial N_{1}}{\partial z} \frac{\partial N_{2}}{\partial z} \frac{\partial N_{3}}{\partial z}\end{array}\right]=\frac{1}{2 A}\left[\begin{array}{ccc}b_{1} & b_{2} & b_{3} \\ c_{1} & c_{2} & c_{3}\end{array}\right]$

the heat conductivity matrix

$$
\mathbf{D}=\left[\begin{array}{cc}
\lambda_{r} & 0 \\
0 & \lambda_{z}
\end{array}\right]
$$

and the basis functions matrix $\mathbf{N}$

$$
\mathbf{N}=\left[\begin{array}{lll}
N_{1} & N_{2} & N_{3}
\end{array}\right] .
$$

The load vector $\vec{b}$ consists of inner heat sources and the boundary conditions

$$
\vec{b}=\int_{V} \dot{e} \mathbf{N}^{\mathbf{T}} d V+\int_{O} \dot{q} \mathbf{N}^{\mathbf{T}} d O+\int_{O} \alpha \vartheta_{a} \mathbf{N}^{\mathbf{T}} d O
$$

Applying the Galerkin method (a form of weighted residual method) to Eq. (2) one yields the following equation

$$
\int_{V} \mathbf{N}\left[\frac{1}{r} \lambda_{r} \frac{\partial}{\partial r}\left(r \frac{\partial \vartheta}{\partial r}\right)+\lambda_{z} \frac{\partial^{2} \vartheta}{\partial z^{2}}+\dot{e}\right] d V=0
$$

which can also be written as the finite element equation with $\vec{u}^{T}=\left[\vartheta_{1} \vartheta_{2} \vartheta_{3}\right]$

$$
\mathbf{S} \vec{u}=\vec{b} .
$$

The global stiffness matrix and the global load vector are formed by adding the corresponding elements of neighboring triangles. The global finite element equation can then be set up and solved.

\subsection{Implementation in Modelica}

Due to the axisymmetry of the heat transfer inside the cell, the temperature does not depend on the angle $\varphi$. Only longitudional flow of the coolant can be examined with this approach, since for transvers flow the heat transfer coefficient depends on $\varphi$.

The three nodes of the triangular element are represented by connectors with the temperature as a single variable.

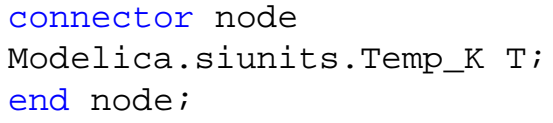

The triangle model consists of the local stiffness matrix $\mathbf{S}$, the local load vector $\vec{b}$, the local temperature vector $\vec{u}$, three nodes, their geometric parameters in cylindrical coordinates and everything necessary to define the heat transfer. Several parameters have the attribute fixed set to false as their value will be set in the aggregated cell model (see next subsection). The convective heat transfer coefficients depend on the medium temperature at the element and are calculated in the cell model, thus they are declared as input variables. The element size can be varied to be able to account for the terminals and the casing of the cell.

The following code listing shows, how two triangles are connected (see Fig. 3). First, the connectors have to be connected. Then the global stiffness matrix and the load and temperature vectors are constructed. The finite element equation is formulated in the global model only.

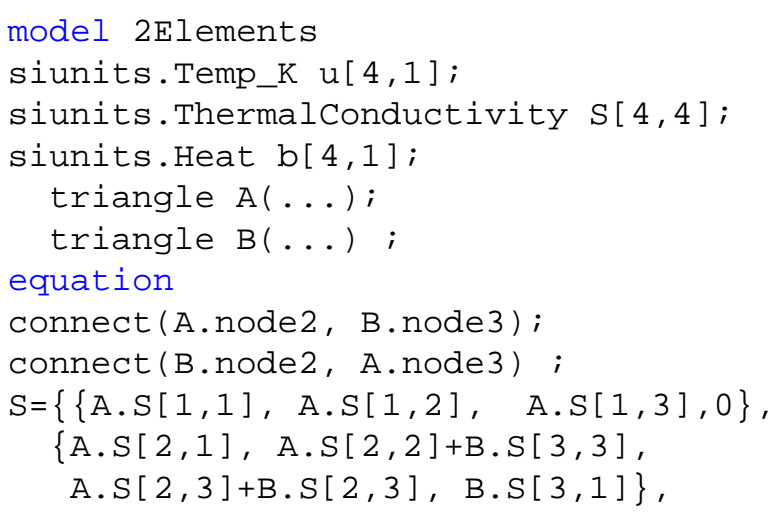




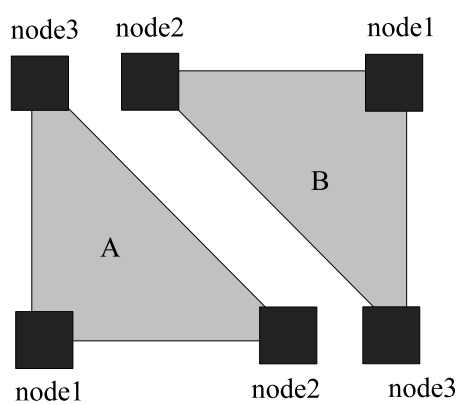

Figure 3: Example 2Elements

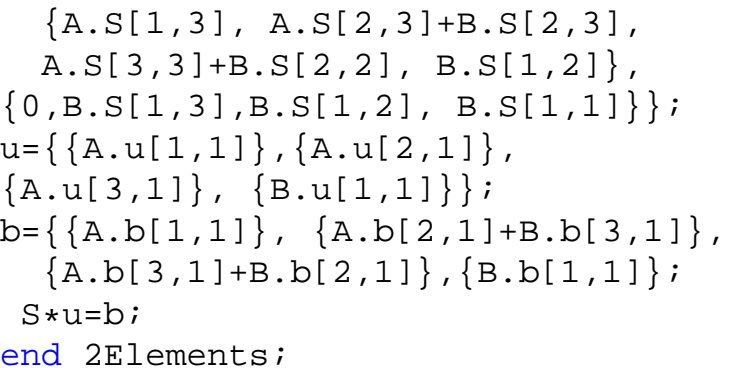

The construction of the global stiffness matrix becomes more and more complicated with a rising number of connected elements. However, once the equations for large stiffness matrices are formulated by means of loops, they can be reused for every other axisymmetric problem if triangular elements with linear basis functions are used.

\subsection{Cell model}

The model for the lithium-ion cell is made up of two arrays of triangles: A and B. Their directions and coordinates are chosen such that e.g. triangle $A[1,1]$ and $\mathrm{B}[1,1]$ are connected to form a rectangle as shown above. All triangles together form the whole cell.

The attempt to take every single layer in the winding into account by at least one element in radial direction would lead to a high number of equations and is therefore dismissed. Instead, the axial and radial heat conductivities are calculated for each layer of sheets as the thermal resistances (axial, radial) vary with the radius. Fig. 4 shows the layers of the winding and the corresponding two triangular elements representing one winding.

For the whole cell a grid with $35 \times 10$ elements with different element sizes is generated. Using a model with more elements leads to an unreasonable increase in simulation time. The cell model can easily be adopted to simulate different cell dimensions. Besides this, the cell materials can be varied. The lid and

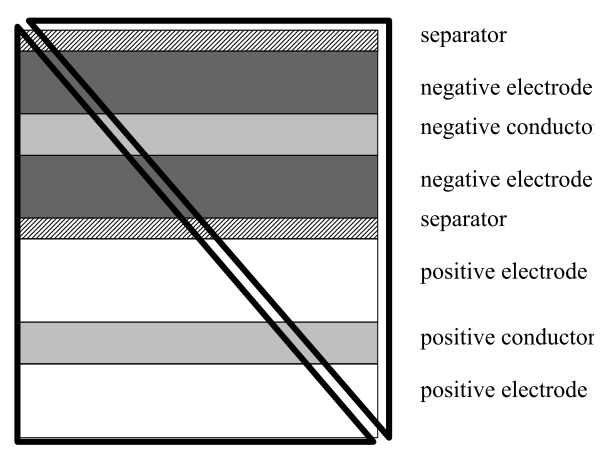

Figure 4: Layers in one winding

the casing of the cell are also taken into account.

\subsection{Coolant model}

As the OpenModelica Compiler does not yet support the Modelica.Media library, simple linear medium models are used to calculate the medium properties. For air, the relative deviation up to $60^{\circ} \mathrm{C}$ is less than $5 \%$ for the relevant properties. Pressure drop of the fluid is neglected.

Fig. 5 illustrates the heat transfer from the cell wall to the fluid. The heat flow from the cell element i to the coolant is described by the following equation

$$
\dot{Q}_{w, i}=\alpha \cdot A \cdot \Delta \vartheta_{i}
$$

with the mean temperature difference

$$
\Delta \vartheta_{i}=\frac{\vartheta_{W, i}+\vartheta_{W, i+1}}{2}-\frac{\vartheta_{C, i}+\vartheta_{C, i+1}}{2}
$$

between the wall temperature $\vartheta_{W}$ and the coolant temperature $\vartheta_{C}$.

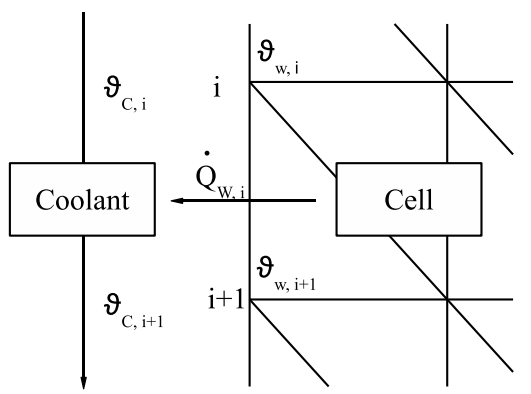

Figure 5: Heat transfer from cell to fluid

The convective heat transfer coefficient $\alpha$ is calculated from a Nusselt number relationship for longitudional flow along a cylinder [3]. As the coolant flows 
along the cell, the fluid is heated up:

$$
\vartheta_{C, i+1}=\vartheta_{C, i}+\frac{\dot{Q}_{W, i}}{\dot{m} c_{p}} .
$$

The temperature difference between cell wall and fluid decreases, less heat can be transferred to the fluid.

At the caps at the top and the bottom of the cell, only natural convection is taken into account (Fig. 2).

The calculated heat flow out of the cell is added to the load vector $\vec{b}$.

\section{Comparison of Coolants}

The coolant type, flow velocity, temperature and flow direction were varied for different simulations. The objective was to find a configuration that fulfills the benchmarks for maximum and mean temperature, together with the maximum temperature difference, as specified in Section 2. The coolants investigated were air, 25 and $38 \%$ (v/v) aqueous propylene glycol, and a silicone oil. Further details of the analyses may be found in [1].

In the simulations, it is assumed that the cell is constantly charged or discharged. The amount of heat generated inside the cell is approximated by a relation given by Gibbard [9]. For moderate loading rates, the heat generation is about $200 \mathrm{~kW} / \mathrm{m}$. For very fast charging/discharging, the heat generation is about $300 \mathrm{~kW} / \mathrm{m}$.

\subsection{Air Cooling}

The first set of simulations was performed for air cooling. Fig. 6 shows the result for an air flow velocity of $5 \frac{\mathrm{m}}{\mathrm{s}}$, an inlet temperature of $20^{\circ} \mathrm{C}$ and a heat generation of $200 \mathrm{~kW} / \mathrm{m}$. The coolant flows upwards along the right-hand side of the diagram; the left-hand side represents the center line of the cell. The maximum temperature exceeds the thermal runaway limit, and the maximum temperature difference greatly exceeds the 5 deg $\mathrm{C}$ limit (see Table 2). The heat transfer coefficient decreases in the flow direction, so that the hottest cell zone is close to the center line in the upper half of the cell, and heat is predominantly removed through the cap at the coolant inlet. Since the forced convective heat transfer is considerably greater than the natural convective heat transfer at the caps, most of the heat is conducted radially to the coolant within the caps. The isotherms are almost parallel within the electrolyte-filled cavity along the center line of the cell, as no heat is generated there. Some of the

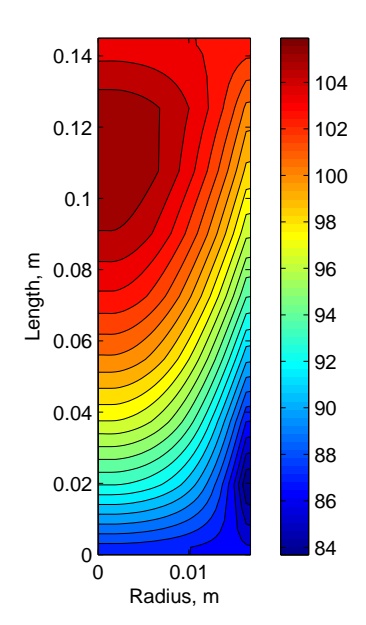

Figure 6: Temperature field for air cooling with a flow velocity of $5 \frac{\mathrm{m}}{\mathrm{s}}$, an inlet temperature of $20^{\circ} \mathrm{C}$ and $200 \mathrm{~kW} / \mathrm{m}^{3}$ heat generation

heat from the cell is transported to the caps within this cavity.

Chen et al. [5] state that radiative heat transfer should be taken into account when modeling surface heat transfer. This applies to cooling with air, whose optical thickness is low. When liquid coolants are used, radiative heat transfer is neglected because of the higher optical thickness. A simple model which assumes grey Lambert bodies for a single cell was used to demonstrate the influence of radiative heat transfer for cells located in the outermost regions of the battery pack.

For the same boundary conditions as in Fig. 6, the maximum temperature is reduced from $105.9^{\circ} \mathrm{C}$ to $82.7^{\circ} \mathrm{C}$, and the maximum temperature difference is reduced from $22.2 \mathrm{deg} \mathrm{C}$ to $17.8 \mathrm{deg} \mathrm{C}$, see Fig. 7 and Table 2.

Table 2: Characteristic temperatures of the different simulations. A: air, inlet flow velocity $5 \mathrm{~m} / \mathrm{s}$, inlet temperature $10^{\circ} \mathrm{C}, 200 \mathrm{~kW} / \mathrm{m}^{3}$ heat generation

\begin{tabular}{lccc}
\hline & $\begin{array}{c}\vartheta_{\max } \\
{ }^{\circ} \mathrm{C}\end{array}$ & $\begin{array}{c}\vartheta_{\text {avg }} \\
{ }^{\circ} \mathrm{C}\end{array}$ & $\begin{array}{c}\Delta \vartheta_{\max } \\
\operatorname{deg~C}\end{array}$ \\
\hline Fig. 6 & 105.9 & 97.6 & 22.2 \\
Fig. 7 & 82.7 & 75.9 & 17.8 \\
A & 95.6 & 87.3 & 22.2 \\
Fig. 8 & 31.5 & 25.9 & 11.1 \\
Fig. 9 left & 42.0 & 33.8 & 16.6 \\
Fig. 9 right & 41.6 & 33.3 & 16.3 \\
\hline
\end{tabular}

Another way of lowering the cell temperature is to reduce the inlet temperature. A simulation was con- 


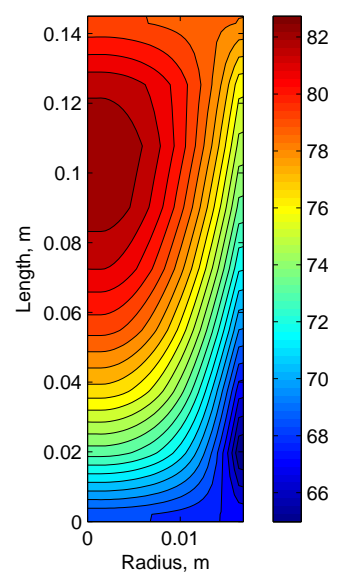

Figure 7: Temperature field for cooling with air at a flow velocity of $5 \frac{\mathrm{m}}{\mathrm{s}}$, an inlet temperature of $20^{\circ} \mathrm{C}$ and $200 \mathrm{~kW} / \mathrm{m}^{3}$ heat generation, taking radiative heat transfer into account

ducted for an air flow velocity of $5 \frac{\mathrm{m}}{\mathrm{s}}$, an inlet temperature of $10^{\circ} \mathrm{C}$ and a heat generation of $200 \mathrm{~kW} / \mathrm{m}^{3}$ (see Table 2, case A). Comparison with Fig. 6 shows that the temperature reduction within the cell is approximately equal to the inlet temperature reduction. The higher energy demand of the refrigeration cycle in order to cool the fluid below ambient temperature should be noted.

No air cooling configuration has been found that keeps the temperature within the permissible temperature range. Air cooling is therefore not recommended for the stationary case.

\subsection{Cooling with $38 \%(v / v)$ Aqueous Propy- lene Glycol}

Aqueous propylene glycol is used as a coolant in internal combustion engines. The thermal capacity of glycol is higher than for air, so the flow velocity is reduced. The result of a simulation for an inlet flow velocity of $1 \frac{\mathrm{m}}{\mathrm{s}}$, an inlet temperature of $20^{\circ} \mathrm{C}$ and a heat generation of $200 \mathrm{~kW} / \mathrm{m}^{3}$ is shown in Fig. 8 .

The high heat transfer coefficients lead to a considerable improvement in thermal performance. The mean temperature of $25.9{ }^{\circ} \mathrm{C}$ and maximum temperature of $31.5^{\circ} \mathrm{C}$ are both within limits; the maximum temperature difference of $11.1 \mathrm{deg} C$ exceeds the limit. Temperature benchmarks are nearly satisfied, and temperature management is possible.

The heat generation is increased to $300 \mathrm{~kW} / \mathrm{m}^{3}$, which corresponds approximately to a charging rate that allows 20 complete chargings and dischargings

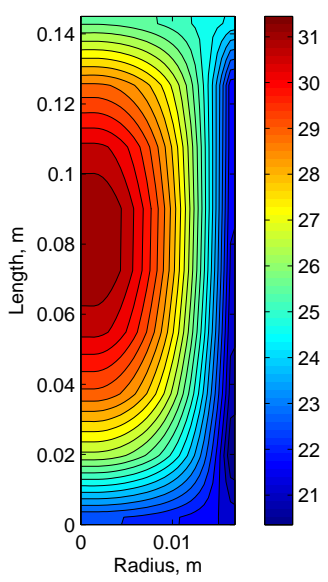

Figure 8: Temperature field for cooling with $38 \%(\mathrm{v} / \mathrm{v})$ aqueous propylene glycol at a flow velocity of $1 \frac{\mathrm{m}}{\mathrm{s}}$, an inlet temperature of $20^{\circ} \mathrm{C}$ and $200 \mathrm{~kW} / \mathrm{m}^{3}$ heat generation

per hour. Fig. 9 shows the effect of varying the inlet flow velocity for an inlet temperature of $25^{\circ} \mathrm{C}$ and $300 \mathrm{~kW} / \mathrm{m}^{3}$ heat generation.

An increase in flow velocity from $1 \frac{\mathrm{m}}{\mathrm{s}}$ to $1.5 \frac{\mathrm{m}}{\mathrm{s}}$ reduces the temperature within the cell only slightly, by about $0.5^{\circ} \mathrm{C}$. This is because the wall temperature is already close to the coolant temperature. Increasing the coolant flow velocity above $1 \frac{\mathrm{m}}{\mathrm{s}}$ is thus of minor advantage for temperature control.

A change in inlet temperature has a considerable and therefore useful influence upon cell temperature. Reducing the inlet temperature to $15^{\circ} \mathrm{C}$ results in a maximum cell temperature of $32.2^{\circ} \mathrm{C}$ and a mean temperature of $24.0^{\circ} \mathrm{C}$, temperatures which are very close to the benchmark temperature. The maximum temperature difference of $16.6 \mathrm{deg} \mathrm{C}$ still exceeds the limit (see Table 3, case B).

To reduce the maximum temperature difference within the cell even further, a change in cell geometry must be considered. This may involve cell material, external diameter and length, and also the dimensions of internal components or the thickness of the caps. Changes in cell design have been evaluated in [1].

To ensure safe operation, the maximum temperature within the cell should never exceed the critical temperature of $60^{\circ} \mathrm{C}$. simulations have shown that, when cooling with $38 \%(\mathrm{v} / \mathrm{v})$ aqueous propylene glycol at a flow velocity of $1 \frac{\mathrm{m}}{\mathrm{s}}$ and with a heat generation of $300 \mathrm{~kW} / \mathrm{m}^{3}$, the maximum inlet temperature is $43^{\circ} \mathrm{C}$. 

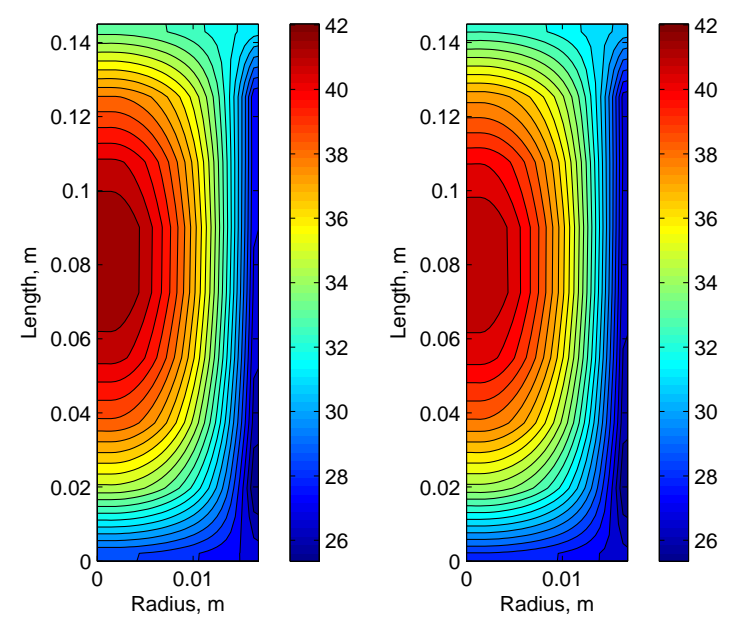

Figure 9: Comparison of temperature fields for cooling with $38 \%(\mathrm{v} / \mathrm{v})$ aqueous propylene glycol at a flow velocity of $1 \frac{\mathrm{m}}{\mathrm{s}}$ (left) and $1.5 \frac{\mathrm{m}}{\mathrm{s}}$ (right), an inlet temperature of $25^{\circ} \mathrm{C}$ and $300 \mathrm{~kW} / \mathrm{m}^{3}$ heat generation

\subsection{Comparison with other Coolants}

To show the effect of different coolants, simulations with $25 \%(\mathrm{v} / \mathrm{v})$ aqueous propylene glycol and Syltherm 800 were performed. Fig. 10 shows a comparison between all three coolants for an inlet flow velocity of $1 \frac{\mathrm{m}}{\mathrm{s}}$, an inlet temperature of $25^{\circ} \mathrm{C}$ and a heat generation of $300 \mathrm{~kW} / \mathrm{m}^{3}$. The propylene glycol concentration is seen to have only a minor influence on the temperature, whilst the use of Syltherm 800 silicone oil results in much higher temperatures.

Table 3: Characteristic temperatures of the different simulations. B: $38 \%(\mathrm{v} / \mathrm{v})$ aqueous propylene glycol, inlet flow velocity $1 \frac{\mathrm{m}}{\mathrm{s}}$, inlet temperature $15^{\circ} \mathrm{C}$, $3300 \mathrm{~kW} / \mathrm{m}^{3}$ heat generation

\begin{tabular}{lccc}
\hline & $\begin{array}{c}\vartheta_{\max } \\
{ }^{\circ} \mathrm{C}\end{array}$ & $\begin{array}{c}\vartheta_{\text {avg }} \\
{ }^{\circ} \mathrm{C}\end{array}$ & $\begin{array}{c}\Delta \vartheta_{\max } \\
\operatorname{deg~C}\end{array}$ \\
\hline B & 32.2 & 24.0 & 16.6 \\
Fig. 10 left & 36.4 & 30.9 & 11.1 \\
Fig. 10 center & 36.1 & 30.6 & 11.0 \\
Fig. 10 right & 40.7 & 34.9 & 13.4 \\
\hline
\end{tabular}

\section{Conclusion}

The stationary thermal model simulates the twodimensional temperature distribution within the cell for natural and forced convective as well as for radiative heat transfer. It can be easily adapted to other cell
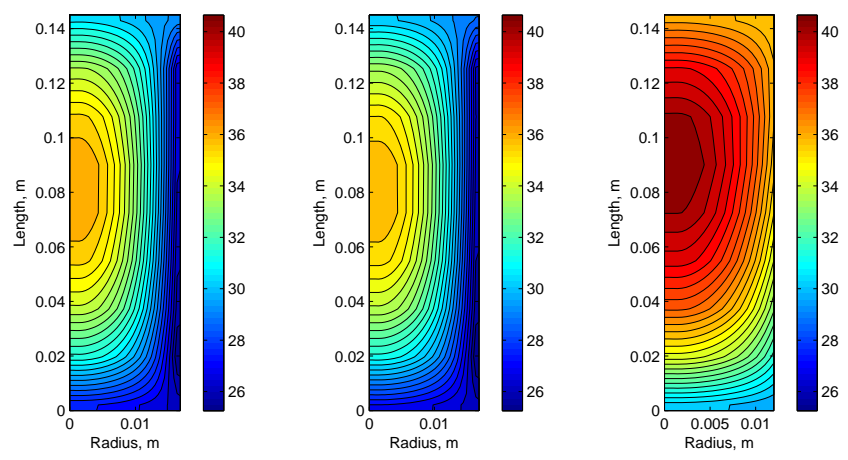

Figure 10: Comparison of temperature fields for cooling with 38 (left), $25 \%(\mathrm{v} / \mathrm{v})$ aqueous propylene glycol (center) and Syltherm 800 (right) at inlet flow velocity of $1 \frac{\mathrm{m}}{\mathrm{s}}$, an inlet temperature of $25^{\circ} \mathrm{C}$ and $300 \mathrm{~kW} / \mathrm{m}^{3}$ heat generation

geometries, and can therefore be used to simulate other cell designs.

simulations show that air cooling is insufficient to keep temperatures within the required limits. Meanwhile, liquid coolants keep the maximum and mean temperature within the desired range for a heat generation of $200 \mathrm{~kW} / \mathrm{m}^{3}$, and thus ensure safe cell operation. The cell cannot be operated safely at a heat generation of $300 \mathrm{~kW} / \mathrm{m}^{3}$.

The simulation of heat transfer with the finite element method has been succesfully implemented in Modelica. Various cylindrical bodies can be modeled. The quality of the model is only limited by the maximum number of equations that can be handled by the tool. The construction of the global stiffness matrix is quite complex, but can be reused for other cylindrical models.

The modeling attempt was also tested with the OpenModelica Compiler. Arrays with large dimensions could not be succesfully simulated, the model for the whole cell can therefor not be translated. For small models consisting of four triangles, the simulation was possible. Only little modifications of the models were necessary.

The introduction of a capacitance matrix into each element would enlarge the range of application to dynamic problems as well.

Smaller numbers of equations can be reached by using different element types for the inside (only heat conduction) and the outside of the cell (additional heat transfer by convection and radiation). 


\section{References}

[1] Sievers, M.: Modellierung der Temperaturverteilung in Lithium-Ionen-Batterien mit der Finite-Elemente-Methode. Bachelor thesis, Hamburg University of Technology, Department of Mechanical Engineering, 2008.

[2] Jossen, A., Weydanz, A.: Moderne Akkumulatoren richtig einsetzen. Reichert Verlag, Untermeitingen, 2006.

[3] Verein Deutscher Ingenieure, VDI-Gesellschaft Verfahrenstechnik und Chemieingenieurwesen (GVC): VDI-Wärmeatlas. 10. Auflage, SpringerVerlag, Berlin, 2006.

[4] Julien, C., Stoynov, Z.: Materials for lithium-ion batteries: Proceedings of the NATO Advanced Study Institute on Materials for Lithium-Ion Batteries, Design and Optimization. Sozopol, Bulgaria, September 21 - October 1, 1999, Kluwer Academic Publishers, Dordrecht, 2000.

[5] Chen, S.-C., Wang, Y.-Y., Wan, C.-C.: Thermal Analysis of Spirally Wound Lithium Batteries. Journal of the Electrochemical Society, 153 (2006) 4, pp. A637-A648.

[6] Al-Hallaj, S., Maleka, H., Selman, J. S.: Thermal modeling and design considerations of lithiumion batteries. Journal of Power Sources, 83 (1999) 1-2, pp. 1-8.

[7] Wu, M.-S., Liu, K.H., Wang, Y.-Y., Wan, C.-C.: Heat dissipation design for lithium ion batteries. Journal of Power Sources, 109 (2002) 1, pp. 160166.

[8] Lewis, R. W., Nithiarasu, P., Seetharamu, K. N.: Fundamentals of the Finite Element Method for Heat and Fluid Flow, John Wiley, Chichester, 2004.

[9] Gibbard, H. F.: Thermal properties of battery systems, Journal of the Electrochemical Society, 125 (1978), pp. 353-358. 